\title{
Effects of reinstatement procedures on retention of differential appetitive responding
}

\author{
SUZANNE V. GATTI, NANETTE PAIS, and JAMES R. WEEKS, JR. \\ Virginia Polytechnic Institute and State University, Blacksburg, Virginia 24061
}

\begin{abstract}
Forty male hooded rats received single alternation runway training followed by a 24-day retention interval. On the 25th retention day, reinstatement procedures (re-exposure to the stimuli from original training) were administered: Groups IRA and ORA $(\mathrm{N}=10$ each) received 10 alternating reward and nonreward placements into a goalbox similar to that of the runway; controls, IRC and ORC (N = 10 each) received 10 placements into an empty neutral box. For half of each group, placements occurred either inside or outside of the experimental room (IR or OR). All rats then received single alternation retraining. Results showed that the alternation-reinstatement procedure reliably facilitated recall and relearning of alternation responding. Retention was minimally affected by the experimental room stimuli alone. However, retention was greatest when the alternation-reinstatement procedure occurred inside the experimental room (Group IRA).
\end{abstract}

Retrieval models of memory (Spear, 1973) propose that forgetting does not result from inappropriate or inadequate storage of information but rather from the inadequate retrieval of originally stored information. Inadequate retrieval may be due to the failure of retention tests to reinstate sufficiently the stimulus conditions (attributes) of original training (Spear, 1973; Underwood, 1969). Studies of the effects of reinstatement procedures on retention have shown that prior to the test of retention, partial reinstatement of the conditions of original training generally facilitates retention of responding (Campbell \& Jaynes, 1969; Silvestri, Rohrbaugh, \& Riccio, 1970).

In a recent review of infrahuman studies of the effects of reinstatement procedures on retention, Spear (1973) showed that most research on reinstatement effects has employed aversive conditioning procedures. These data generally show that retention of aversively motivated behavior is facilitated by brief re-presentation of the aversive stimuli of prior learning. In these studies, reinstatement procedures typically consisted in noncontingent exposure either to UCS (Klein \& Spear, 1970 ) or to CS (Silvestri, Rohrbaugh \& Riccio, 1970) components from original training or exposure to contextual stimuli (e.g., apparatus cues) similar to those of original learning (DiCara \& Miller, 1968).

From Spear's review, it seems that little attention has been paid to the effects of reinstatement procedures on retention of appetitively learned behavior. However, evidence that reinstatement procedures may facilitate such retention is suggested by several sources. Spear (1967) indicated that following a retention interval re-exposure to the reinforcer from original training

Joseph J. Franchina sponsors and takes full editorial responsibility for this paper. Requests for reprints should be addressed to Joseph J. Franchina, Department of Psychology, Virginia Polytechnic Institute and State University, Blacksburg, Virginia 24061. This paper was presented to the meeting of Southeastern Psychological Association, Atlanta, March, 1975. enhanced retention of the original instrumental behavior. Studies employing reinstatement of a visual-discrimination appetitive task (Campbell \& Jaynes, 1969) or noncontingent exposure to the reinforcer between training and testing (Reid, 1958) also suggest that reinstatement procedures would influence retention of more complex appetitive behavior, like differential responding, the present study investigated the effects of reinstatement on retention of alternation behavior.

Instrumental training under alternating reward (R) and nonreward $(\mathrm{N})$ eventually yields slower running on trials following reward than on trials following nonreward. According to Capaldi $(1967,1971)$, this alternation behavior is due to differential conditioning of instrumental responding to the distinctive internal aftereffects of reward and nonreward. Further, Capaldi proposes that the influence of aftereffects on differential responding is a direct function of environmental contextual cues present during instrumental training. Presumably, the greater the similarity of contextual stimuli from one instrumental trial to the next, the more rapidly alternation behavior develops (Capaldi, 1971).

Environmental contextual cues may consist in those present inside of the training apparatus (intra-apparatus cues) or those outside of the apparatus (e.g., extra-apparatus cues from the experimental room). Although Capaldi has emphasized the role of intra-apparatus cues in alternation performance, relatively little concern has been directed at the role of extra-apparatus cues. The purpose of the present study was to investigate whether or not reinstatement procedures would influence the retention of differential (alternation) responding and whether extra-apparatus cues would influence reinstatement effects.

\section{METHOD}

\section{Apparatus}

The apparatus was essentially that described by Franchina and 


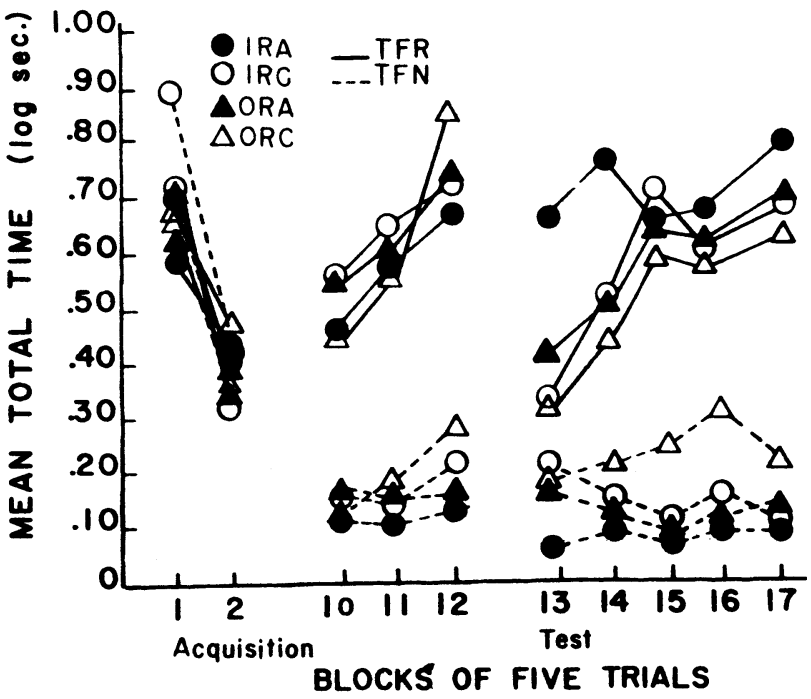

Figure 1. Mean log total time in blocks of five trials following reward (TFR) and following nonreward (TFN) for IRA, IRC, ORA, and ORC groups.

Brown (1970). Briefly, a black alleyway (137 cm long) with a grid floor and clear Plexiglas top was divided by a guillotine door into runway and goalbox $(25 \mathrm{~cm} \times 13 \mathrm{~cm} \times 10 \mathrm{~cm})$ sections. The goalbox was attached to the runway by a 90 -deg left turn. At the rear of the goalbox was a removable foodcup $(4 \mathrm{~cm}$ diam and $2 \mathrm{~cm}$ deep). Directly behind the goalbox, but out of view, were two portable boxes. One box was highly similar to the goalbox of the alleyway $(25 \mathrm{~cm} \times 13 \mathrm{~cm} \times 10 \mathrm{~cm})$. The other box $(31 \mathrm{~cm} \times 31 \mathrm{~cm} \times 31 \mathrm{~cm})$ was constructed of solid Plexiglas lined with brown paper and called the neutral box (NB).

Instrumental performance in the alleyway was measured by photocells in circuit with a timer (calibrated in $.01 \mathrm{sec}$ ). One photocell was located in the runway section $6 \mathrm{~cm}$ from the point at which the rat was inserted in to the apparatus. The second photocell was located $110 \mathrm{~cm}$ from the first and approximately $5 \mathrm{~cm}$ in front of the guillotine door. Insertion of the rat into the apparatus interrupted the first photobeam, starting the timer. Interruption of the second beam stopped the timer, thereby providing a measure of total running time.

\section{Subjects}

The subjects were 40 experimentally naive male hooded rats, 90-120 days old, from the local departmental colony. Throughout the experiment, each rat was housed individually and was maintained on a feeding regimen of $10 \mathrm{~g}$ of wet mash/day administered in the home cage at least $15 \mathrm{~min}$ after daily treatments. The wet mash was $10 \mathrm{~g}$ of ground chow mixed with 3 tablespoons of water. Water was always available in the home cage.

\section{Design and Procedure}

After 4 days of handling and habituation to the feeding regimen, each rat received 2 days of apparatus exploration: $5 \mathrm{~min}$ on the $1 \mathrm{st}$ day, $3 \mathrm{~min}$ on the 2 nd day. The photocells and timer were on; the guillotine door was open. On the 2 nd day of exploration, the rats also received two baited goalbox placements. For a goalbox placement, the rat was hand carried to the goalbox and placed head down directly over the foodcup. Beginning on the day after exploration ended, all rats received 13 days of single alternation (SA) training; 4 trials on Day 1, 6 trials the following day, and 10 trials/day on the next 11 days. In SA training, odd-numbered trials were rewarded; even-numbered trials, nonrewarded. For a trial, the rat was inserted into the apparatus directly over the first photobeam. The rat then had $40 \mathrm{sec}$ to traverse the runway and interrupt the second photobeam. Rewarded trials provided $30 \mathrm{sec}$ of goalbox confinement with wet mash in the foodcup. Nonrewarded trials provided $30 \mathrm{sec}$ of goalbox confinement with a similar empty foodcup. The intertrial interval was $20 \mathrm{sec}$ spent in a white holding box $(22 \mathrm{~cm} \times 20 \mathrm{~cm} \times 18 \mathrm{~cm})$. If the rat failed to interrupt the second photobeam within $40 \mathrm{sec}$, the trial was terminated, and a latency of $40 \mathrm{sec}$ was recorded. On such trials, the guillotine door was lowered, and the rat was placed into the goalbox for the appropriate reward $(\mathrm{R})$ or nonreward $(\mathrm{N})$ condition.

Following the last day of training, each rat was placed into its home cage and confined for a 24-day retention interval. During the retention interval, the rats were maintained on the feeding regimen, but they were not handled. On the 25 th day of retention, the rats were randomly assigned to reinstatement conditions. Half of the rats $(\mathrm{N}=20)$ received 10 placements under alternating $\mathrm{R}$ and $\mathrm{N}$ in to the goalbox which was similar to that of the alleyway (the A condition). The other half of the rats $(\mathrm{N}=20)$ received 10 placements into an empty neutral box (the $\mathrm{C}$ condition). For half of the rats $(\mathrm{N}=10)$ in each of these conditions, placements occurred inside of the experimental room (IR). For the other half, placements occurred outside the room (OR). The OR condition was a $31 \mathrm{~m} \times 37 \mathrm{~m}$ animal holding area containing two racks of 60 rats each. Thus, the design of this experiment was a 2 by 2 factorial, the main factors being reinstatement procedures and environmental room conditions.

On the day following reinstatement procedures, all rats received 10 trials of alternation training on each of the next 5 days. Procedures followed those of original training. The measure of performance, total running time, was transformed into logarithms (Bloom \& Capaldi, 1961).

\section{RESULTS}

Figure 1 presents mean log total time in blocks of five trials following reward (TFR) and nonreward (TFN) for the first 2 and last 3 acquisition days and for the 5 retention test days. All groups demonstrated SA responding in acquisition, TFR/TFN by Trial Blocks, $F(11,396)=2.34, p<.01$.

Considering retention, Figure 1 shows facilitated alternation performance for Groups IRA and ORA on Test Day 1 relative to IRC and ORC controls. On Day 2, all groups demonstrated greater SA responding; but this increase was minimal for Group ORC. By the end of testing, all groups performed similarly to each other and at a level comparable to that of terminal acquisition. Analysis of variance over all the data of the test days showed reliable interactions, TFR/TFN by Reinstatement Condition, $\mathrm{F}(1,36)=7.39, \mathrm{p}<.01$; TFR/TFN by Room Condition, $\mathrm{F}(1,36)=4.11, \mathrm{p}<.05$; and TFR/TFN by Trials Blocks, $F(4,144)=3.47$, $\mathrm{p}<.01$. To investigate these interactions further, analyses on Trial Blocks 1 and 5, separately, were performed. The analysis of Trial Block 1 data yielded a reliable interaction of TFR/TFN by Reinstatement Condition, $F(1,36)=7.39, p<.01$. Separate analysis of TFR and TFN revealed a reliable effect of reinstatement condition in each case, TFN, $\mathrm{F}(1,36)=4.11, \mathrm{p}<.05$ and TFR, $F(1,36)=7.39,<.01$. Comparisons between TFR and TFN for each group revealed reliable 
differences for Groups IRA, ORA, ORC, $\mathrm{F}(1,9)=10.56$, 5.12 , and $5.12 ; \mathrm{p}<.01,<.05,<.05$. No reliable TFR/TFN difference occurred for IRC in magnitude of SA responding. Analysis of the data on Trial Block 5 yielded only a reliable TFR/TFN effect, $F(1,36)=7.39$, $\mathrm{p}<.01$.

To provide a more detailed analysis of performance early in retention testing, Figure 2 presents the single trial data for the first 2 retention days. Trial 1 of Test Day 1 shows a marked facilitation of alternation performance for Groups IRA and ORA, relative to Groups IRC and ORC. The combination of alternation reinstatement procedure and experimental room condition (Group IRA) yielded the greatest facilitation. Analysis of variance of the data of Trial 1 showed only a TFR/TFN by Reinstatement Condition interaction, $F(1,36)=7.39, p<.01$. Comparison of performance of reward Trial 1 and of nonreward Trial 1 for each group revealed a reliable difference for Group IRA, $t(9)=3.25$, $\mathrm{p}<.005$ and Group ORA, $\mathrm{t}(9)=2.26, \mathrm{p}<.05$, but not for Groups IRC and ORC. Analysis over all the single trial data of Test Day 1 yielded a reliable interaction of TFR/TFN by Reinstatement Condition, $F(1,36)=7.39$, $\mathrm{p}<.01$ and Trials Effect, $F(4,144)=3.47, p<.01$. There were no reliable effects for the room condition. Further analyses evaluated the TFR/TFN by Reinstatement Condition interaction. Comparisons between experimental and control groups on TFR and TFN separately revealed only a reliable trials effect, $F(4,72)=3.56, p<.01$ for TFN. There were no reliable findings for TFR. An overall analysis of variance over single trial data of Test Day 2 yielded reliable interactions of TFR/TFN by Reinstatement Condition and TFR/TFN by Room Condition, $F(1,36)=4.11$, $\mathrm{p}<.05$.

\section{DISCUSSION}

This study demonstrated that reinstatement procedures facilitated retention of alternation responding. Retention was greatest for Group IRA which received the alternation reinstatement procedure inside the experimental room. In fact, throughout testing, Group IRA showed alternation responding at a magnitude similar to that of terminal acquisition. All other groups needed several trials but eventually showed alternation performance levels similar to those of terminal acquisition. Poorest retention was shown by the group which received placements into an empty neutral box outside of the experimental room (Group ORC).

In this study, retention effects were observed on Trial 1 of Test Day 1 as well as on later test trials. Since Trial 1 of reward and of nonreward occurred following the retention interval, these data could be construed as reflecting the recall of original responding (Gleitman, 1971). Beginning on the second trial of reward and of nonreward, instrumental performance presumably reflected relearning as well as recall factors. In terms of these indices, it appears that the alternation reinstatement procedure affected both recall and relearning. Specifically, on Trial 1 of Test Day 1, the groups which received the alternation reinstatement procedure (IRA and ORA) showed a greater difference in performance between rewarded and nonrewarded trials than did the control groups (IRC and ORC). The greatest

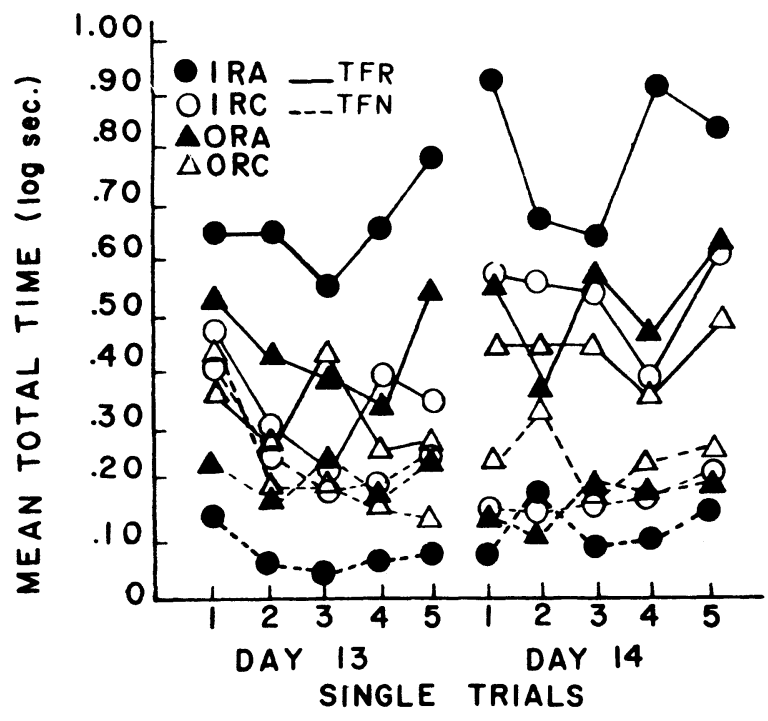

Figure 2. Mean log total time in single trials following reward (TFR) and following nonreward (TFN) for IRA, IRC, ORA, and ORC groups.

difference was shown by Group IRA, which had the alternation reinstatement procedure conducted inside the experimental room. Presumably, these procedures maximized the stimulus similarity between the conditions of original training and those of reinstatement. For the control groups, IRC showed no reliable differences between reward and nonreward on Trial 1, and ORC showed reliable TFR/TFN differences in a direction opposite to SA responding. After Trial 1, relearning was greatest for Group IRA, while Groups ORA, IRC, and ORC responded at lower levels and similarly to each other. Descriptively speaking, a comparison of Group ORA with Groups IRC and ORC showed that retention was negligibly affected by the extra-apparatus (room) factors alone. Considering these data, the present study demonstrated that retention was greatest when the alternation reinstatement procedure was conducted inside the experimental room. Thus, both the internal stimuli from the reward-nonreward sequence and the external contextual stimuli contributed jointly to retention. These results were consistent with Spear's (1973) view that the more completely the reinstatement procedures reproduce the stimulus conditions of original training, the greater the facilitation of retention (retrieval) of the originally trained response.

\section{REFERENCES}

Bloom, D. J., \& Capaldi, E. J. The behavior of rats in relation to complex patterns of partial reinforcement. Journal of Comparative and Physiological Psychology, 1961, 54, 261-265.

Campbell, B. A., \& Jaynes, J. Effect of duration of reinstatement on retention of a visual discrimination learned in infancy. Developmental Psychology, 1969, 1, 71-74.

Capaldi, E. J. A sequential hypothesis of instrumental learning. In K. W. Spence and J. Spence (Eds.), Recent advances in learning and motivation. New York: Academic Press, 1967.

Capaldi, E. J. Memory and learning: A sequential viewpoint. In W. K. Honig and P. H. R. James (Eds.), Animal memory. New York: Academic Press, 1971.

DiCara, L. V., \& Miller, N. E. Long-term retention of instrumentally learned heart-rate in a curarized rat. Communications in Behavioral Biology, 1968, 2, 19-23.

Franchina, J. J., \& Brown, T. S. Response patterning and extinction in rats with hippocampal lesions. Journal of Comparative and Physiological Psychology, 1970, 70, 66-72.

Gleitman, H. Forgetting of long-term memories in animals. In W. K. Honig \& P. H. R. James (Eds.) Animal memory. New York: Academic Press, 1971. 
Klein, S. B., \& Spear, N. E. Reactivation of avoidance-learning memory in the rat after intermediate retention interval. Journal of Comparative and Physiological Psychology, 1970, 72, 498-504.

Reid, R. L. The role of the reinforcer as a stimulus. British Journal of Psy chology, 1958, 49, 202-209.

Silvestri, R., Rohrbaugh, M. J., \& Riccio, D. C. Conditions influencing the retention of learned fear in young rats. Developmental Psychology, 1970, 2, 380-395.
Spear, N. E. Retention of reinforcer magnitude. Psychological Review, 1967, 74, 216-234.

Spear, N. E. Retrieval of memory in animals. Psychological Review, 1973, 80, 163-194.

Underwood, B. J. Attributes of memory. Psychological Review, 1969, 76, 559-573.

(Received for publication March 17, 1975.) 